\title{
Plasma Lipid Peroxidation as a Marker for Seminal Oxidative Stress in Stallion
}

\author{
Patricia Wolkmer $^{1}$, Andressa M. G. Stumm ${ }^{1}$, Luiz F. K. Borges ${ }^{1}$, Eduarda P. T. Ferreira ${ }^{1}$, Bruna Favaretto ${ }^{1}$ \\ \& Lucas C. Siqueira ${ }^{1}$ \\ ${ }^{1}$ Veterinary Medicine, University of Cruz Alta, Rio Grande do Sul, Brazil \\ Correspondence: Lucas Carvalho Siqueira, Veterinary Medicine, University of Cruz Alta (UNICRUZ), Campus \\ Rodovia Municipal Jacob Della Méa, km 5.6, Parada Benito Cruz Alta, Rio Grande do Sul, CEP: 98005-972, \\ Brazil. E-mail: lusiqueira@unicruz.edu.br
}

Received: February 24, 2019 Accepted: March 27, 2019 Online Published: May 15, 2019

doi:10.5539/jas.v11n6p401 URL: https://doi.org/10.5539/jas.v11n6p401

\begin{abstract}
This experiment aims to evaluate the correlation between lipid peroxidation levels in serum and seminal plasma in equines. Also, it investigates the lipid peroxidation in extended semen samples and its effects and sperm motility during a $72 \mathrm{hr}$ refrigeration period. Blood and semen were collected from fertile Crioulo stallions. Serum and seminal plasma lipid peroxidation levels were analyzed by thiobarbituric acid reactive substances (TBARS) immediately after semen collection. After addition of extender (hour $=0$ ), diluted semen was refrigerated and stored at $5{ }^{\circ} \mathrm{C}$. Semen analyses, TBARS and catalase activity were performed in extended semen at $0,24,48$, and 72 hours. We noted that levels of plasma lipid peroxidation can be used as an indicative of seminal oxidative stress. Also, lipid peroxidation does not increase substantially during semen storage. Lipid peroxidation and the antioxidant enzyme catalase do not seem to be the major cause of loss and motility and consequently reduction in fertility in stallion semen during storage for $72 \mathrm{~h}$ at $5{ }^{\circ} \mathrm{C}$.
\end{abstract}

Keywords: TBARS, catalase, horse, semen, sperm storage

\section{Introduction}

Semen characteristics and quality can vary greatly among stallions within the breeding population. The low fertility of mares following artificial insemination with cooled semen is reported (Watson, 2000; Aurich, 2005), and it is largely due to the loss of fertilizing ability of spermatozoa. The effects of oxidative stress are particularly important during sperm storage. It has been shown that during low temperature storage, due to the excessive generation of reactive oxygen species (ROS), equine sperm are exposed to oxidative injury to membrane phospholipids, proteins and genetic material (Baumber et al., 2000).

Damage to the spermatozoa plasma membrane results in the irreversible loss of motility and/or fertilizing capability (Baumber et al., 2000; Morris et al., 2000; Ortega Ferrusola et al., 2009; Dos Santos Hamilton et al., 2016). Since these cells have low levels of reactive oxygen species (ROS) scavengers, seminal plasma protects ejaculated equine sperm from the adverse effects of ROS, and therefore the removal of seminal plasma during processing may increase the susceptibility of sperm to oxidative stress (Ball et al., 2001).

Lipid peroxidation seems to be an important source of spermatic damage and its reduction could be advantageous to refrigerated semen during extended periods. The assessment of lipid peroxidation on blood samples could be more practical to perform since it does not require semen collection and manipulation. Therefore, the aim of this experiment is to evaluate if there is correlation between levels of lipid peroxidation on serum and seminal plasma of stallions. It also investigates the production of ROS on diluted semen samples and its effects in sperm motility during a $72 \mathrm{~h}$ refrigeration period.

\section{Material and Methods}

\subsection{Reagents}

Thiobarbituric acid, malondialdehyde, 5,5-dithiobis-2-nitrobenzoic acid (DTNB), sodium dodecyl sulfate and Coomassie brilliant blue G were purchased from Sigma Chemical Co (St. Louis, MO, USA). All other reagents used in the experiments were of analytical grade and of highest purity. 


\subsection{Animals}

Nine fertile Crioulo stallions aged between 6 and 8 years were used for this study. Animals were housed individually, fed hay twice daily; water and mineral supplements were freely available. All animals underwent a clinical general examination and testicular palpation before the experimental period. The Animal Care and Use Committee of University of Cruz Alta, Brazil approved all procedures performed.

\subsection{Blood Collection}

All blood samples were collected from the external jugular vein into glass tubes (Vacutainer tubes). Part of the material collected was allocated in tubes containing anticoagulant (ethylene-diaminetetraacetic acid-EDTA) for performance of hemogram and fibrinogen to guarantee animal health. Serum samples were collected in tubes without anticoagulant and obtained by centrifugation at $2000 \mathrm{~g}$ during ten minutes for thiobarbituric acid reactive substances (TBARS) assays.

\subsection{Semen Collection and Processing}

Semen samples were collected from all stallions using an artificial vagina. Immediately after collection, the gel fraction was removed and semen was filtered. Volume and color of the ejaculate, motility, sperm concentration and $\mathrm{pH}$ were determined. The percentage of progressively motile spermatozoa was assessed with microscope $(400 \times)$ and sperm concentration was determinate using Neubauer chambers. Total sperm count per ejaculate was calculated by multiplying the sperm concentration by the volume of semen in each sample. The $\mathrm{pH}$ was determined with test strips (Merck, Darmstadt, Germany).

To obtain the seminal plasma in the fresh semen, an aliquot sample was centrifuged $(600 \times \mathrm{g}$ for 10 minutes) for lipid peroxidation performance. The sample was immediately diluted in pre-warmed $\left(37^{\circ} \mathrm{C}\right)$ extender (Botu-Crio, Botupharma) to a final concentration of $50 \times 10^{6}$ spermatozoa $/ \mathrm{mL}$. The semen samples were packed into $2 \mathrm{~mL}$ microtubes. Cooling the samples at $5{ }^{\circ} \mathrm{C}$ was performed in passive refrigeration containers (Botutainer, Botupharma, Botucatu, Brazil) with a cooling rate of $0.05{ }^{\circ} \mathrm{C} / \mathrm{min}$ until stabilization at $5{ }^{\circ} \mathrm{C}$. Sperm analyses were performed at $0,24,48$, and 72 hours after initial dilution. TBARS and catalase activity was evaluated in the total sample of extended semen (suspension) after cooling.

\subsection{Analysis of Spermatozoa Motility}

To evaluate the spermatozoa motility, $10 \mu \mathrm{L}$ of samples were pipetted onto microscope slides. Progressive spermatozoa motility was estimated by diluting the semen using $2.9 \%$ trisodium citrate solution so that individual spermatozoa could be visualized ( $\times 400$ magnification). The percentage motility was determined arbitrarily on a 0 to 10 -point scale, where 0 denoted $0 \%$ motility and 10 denoted $100 \%$ motility.

\subsection{Lipid Peroxidation Analysis (TBARS Assay)}

Lipid peroxidation was estimated colorimetrically by measuring TBARS. Serum, seminal plasma and extended semen lipid peroxidation levels were assessed as described by Ohkawa et al. (1979). Initially, $500 \mathrm{~mL}$ of the sample were diluted in $1 \mathrm{~mL}$ of (vol: vol) solution of trichloroacetic acid $50 \mathrm{nM}$ and centrifuged at $16,000 \mathrm{~g}$, for 10 minutes. After centrifugation, $500 \mu \mathrm{L}$ of the supernatant was added to $500 \mu \mathrm{L}$ of a $0.8 \%$ solution of thiobarbituric acid in $0.05 \mathrm{~N}$ sodium hydroxide, plus acetic acid $2.5 \mathrm{M}$ and sodium dodecyl sulfate $8.1 \%$ and incubated for 60 minutes at $100{ }^{\circ} \mathrm{C}$. To quench the reaction, samples were rapidly placed in ice after incubation and centrifuged. The TBARS were measured in a spectrophotometer (GE Healthcare, Amersham Place, United Kingdom) at a 532-nm wavelength. A baseline curve was prepared using a standard solution of malondialdehyde (MDA). Results are expressed in nanograms of MDA per milliliter.

\subsection{Catalase (CAT) Activity}

Catalase activity in extended semen suspension was measured as described by Nelson and Kiesow (1972) with a slight modification. Sperm suspension was homogenized in $50 \mathrm{mM}$ potassium phosphate buffer, $\mathrm{pH} 7.5$ at a proportion $1 / 5(\mathrm{w} / \mathrm{v})$. Decomposition of $30 \mathrm{mmol}$ of $\mathrm{H}_{2} \mathrm{O}_{2}$ was systematically followed by monitoring the decrease in absorbance at $240 \mathrm{~nm}$. The change in absorbance is directly proportional to the measure of catalase activity. The decrease in the absorption was followed for $3 \mathrm{~min}$ and $\mathrm{mmol}_{2} \mathrm{O}_{2}$ degraded per min and defined as $\mathrm{U} / \mathrm{mg}$ protein.

\subsection{Seminal Plasma Protein Thiols}

Measurement of protein thiols in seminal plasma were measured by the spectrophotometric method described by Boyne and Ellman, (1972). The pellet was dissolved in $50 \mathrm{mM}$ phosphate buffer containing $1 \%$ SDS and $50 \mathrm{mM}$ EDTA (pH 7.4). An aliquot of $100 \mathrm{mM} 5,5$-dithiobis-2-nitrobenzoic acid (DTNB) was added. The absorbance at 
$412 \mathrm{~nm}$ was recorded and the protein thiol content was calculated from a standard curve. The value is expressed in the unit of nmole/mL seminal plasma.

\subsection{Data Analysis}

All determinations were obtained from triplicate measurements. Results are expressed as mean \pm standard error. Experimental data were statistically analyzed using software GraphPad Prism, by one-way ANOVA. Differences between means were evaluated for significance using Tukey-test $(p<0.05)$. Pearson's correlation coefficients were used to assess the similarity between the serum and seminal TBARS values.

\section{Results}

At the beginning of the experiment, the average progressive motility was $73.33 \pm 5.83 \%$ and sperm concentration $125.80 \pm 55.32\left(\times 10^{6} / \mathrm{mL}\right)$. Gradual reduction in progressive motility was observed $(\mathrm{p}<0.0001$; Figure 1$)$, with $22.22 \%(2 / 9)$ for the samples presenting less than $10 \%$ of sperm motility at 72 hours.

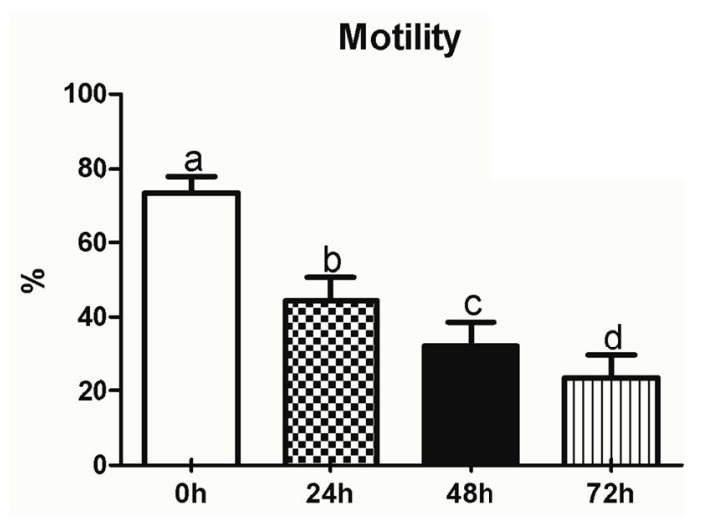

Figure 1. Progressive motility (\%) of extended semen from crioulo stallions during cooled storage. Analyses were performed at $0,24,48$, and 72 hours

Direct correlations between measured values of lipid peroxidation in serum and seminal plasma were observed (Figure 2). On the other hand, there was no correlation between lipid peroxidation and progressive motility on extended semen $(p>0.05)$. Also, no changes were observed on semen lipid peroxidation levels over time (Figure $3)$.

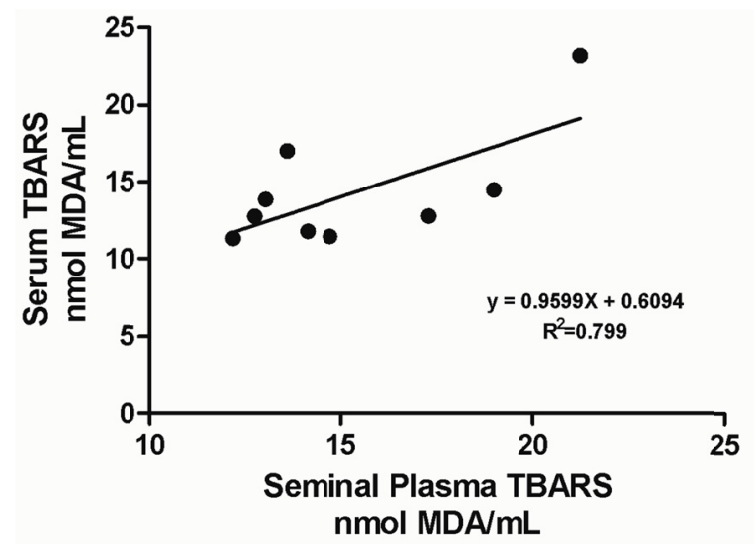

Figure 2. Correlations between lipid peroxidation levels in serum and seminal plasma from Crioulo stallions.

Analyses were performed by thiobarbituric acid reactive substances (TBARS) 


\section{TBARS}

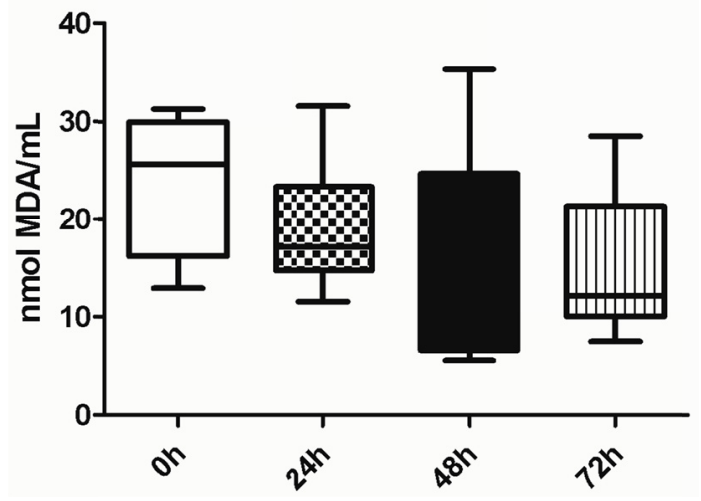

Figure 3. Thiobarbituric acid reactive substances (TBARS) levels in extended semen from 9 stallions analyzed immediately after collection and 24,48 , and $72 \mathrm{~h}$

The CAT activity showed a tendency to decrease $(\mathrm{p}=0.065)$ during the analyzed times (Figure 4). However, there was no correlation of CAT activity values and progressive motility. Nevertheless, the protein thiols did not change during 72 hours analyzed (Figure 5) and content was not directly related to motility. No significant correlation was found between protein thiols content and motility in fresh or after cooling these samples.

\section{Catalase}

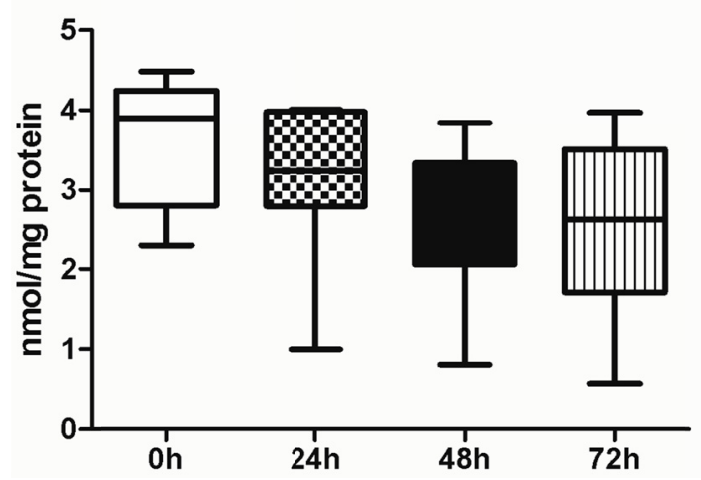

Figure 4. Catalase (CAT) activity in extended semen assays at $0,24,48$, and 72 hours after dilution and storage at $5{ }^{\circ} \mathrm{C}(\mathrm{p}=0.065 ; \mathrm{n}=9)$

\section{Protein thiols}

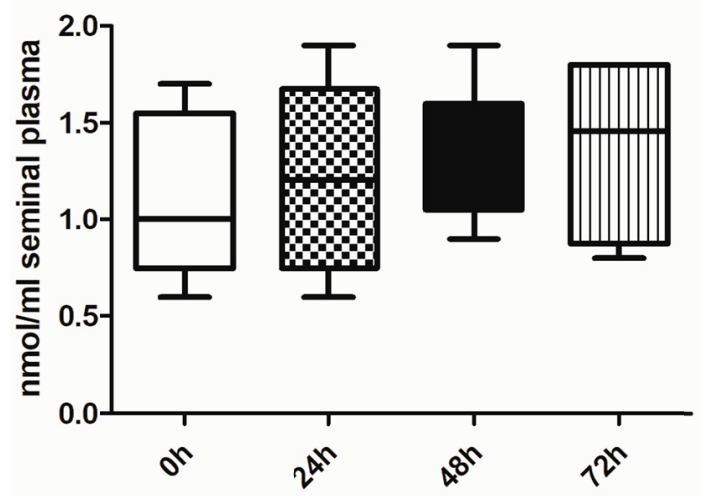

Figure 5. Protein thiols in seminal plasma in extended semen assays at $0,24,48$, and 72 hours after dilution and storage at $5{ }^{\circ} \mathrm{C}(\mathrm{p}>0.05 ; \mathrm{n}=9)$ 


\section{Discussion}

Spermatozoa are susceptible to oxidation of their plasma membranes due to the presence of polyunsaturated fatty acids (Aitken, 1995; Baumber et al., 2000; Kankofer et al., 2005; Aitken et al., 2016). Human studies have shown the toxic lipid peroxides are known to cause membrane damage and reduce motility (Sikka et al., 1995; Walczak-Jedrzejowska et al., 2013). In this study, we sought to evaluate correlation between measured values of lipid peroxidation (TBARS) in blood and seminal plasma, thereby blood markers could be used as a possible analysis of the spermatic function in horses.

Strong correlation between measured values of lipid peroxidation (TBARS) in blood and seminal plasma was observed (Figure 2). The blood analysis could reduce the handling of the semen, which is also an aggravating factor of spermatic damage (Vidament et al., 2000). Reactive oxygen species can be one of the determinant factors of fertility reduction in horses (Johannisson et al., 2014). However, in the present study it was neither observed significant changes in lipid peroxidation levels during the storage of cooled equine semen (Figure 3) nor its correlation with progressive motility. This indicates that lipid peroxidation apparently is not a major factor influencing semen viability during storage at $5{ }^{\circ} \mathrm{C}$. Gibb et al. (2014) argues that the relationship between stallion fertility and oxidative stress remains poorly understood. The relevance of oxidative stress to stallion fertility assessments must be considered carefully, and that, while the symptoms of oxidative stress are never going to be beneficial, they may be indicative of an extremely fertile sample when it remains at subclinical levels. Furthermore, there is great variety of semen extenders and its effect may be significant in the diversity of results for the cooling and oxidative damage in semen (Padilla \& Foote, 1991). Addition of semen extender increases the antioxidative/oxidative capacity of stallion seminal plasma (Kankofer et al., 2005; Asadpour et al., 2011).

Stallion spermatozoa contain high activity of catalase, an antioxidant scavenger, which is derived primarily from prostatic secretions (Ball et al., 2001). During the evaluated period, there was a tendency to reduce activity levels of this antioxidant enzyme on extended semen (Figure 4). This could make the spermatozoa more sensitive to oxidative damage. The beneficial effects of catalase on oxidative stress generated as a result of semen manipulation and cooling have been suggested by studies in various species (Maia et al., 2010; Moubasher et al., 2013). The activity of catalase and superoxide dismutase presents a great variation among stallions in the activities of these scavengers (Baumber et al., 2000; Ball et al., 2001). The removal of seminal plasma during semen processing may increase the susceptibility of sperm to oxidative stress because of the removal of these enzyme scavengers (Padilla \& Foote, 1991; Kankofer et al., 2005). On the other hand, levels of protein thiols were not altered at the time evaluated (Figure 5), these findings suggest the possibility that protein thiols may be functional in the spermatozoa as a protective mechanism against oxidative damage.

In conclusion, levels of plasma lipid peroxidation can be used as an indicative of seminal oxidative stress. Also, lipid peroxidation and the antioxidant enzyme catalase do not seem to be the major cause of loss and motility and consequently reduction in fertility in stallion semen during storage for $72 \mathrm{~h}$ at $5{ }^{\circ} \mathrm{C}$. The extender used may have contributed to reduce the lipids oxidation and to keep antioxidative defense systems protecting the sperm from damage.

\section{References}

Aitken, R. J. (1995). Free radicals, lipid peroxidation and sperm function. Reproduction, Fertility, and Development, 7, 659-668. https://doi.org/10.1071/RD9950659

Aitken, R. J., Gibb, Z., Baker, M. A., Drevet, J., \& Gharagozloo, P. (2016). Causes and consequences of oxidative stress in spermatozoa. Reproduction, Fertility, and Development, 28, 1-10. https://doi.org/ 10.1071/RD15325

Asadpour, R., Jafari, R., \& Tayefi-Nasrabadi, H. (2011). Effect of various levels of catalase antioxidant in semen extenders on lipid peroxidation and semen quality after the freeze-thawing bull semen. Veterinary Research Forum, 2, 218-221.

Aurich, C. (2005). Factors affecting the plasma membrane function of cooled-stored stallion spermatozoa. Animal Reproduction Science, 89, 65-75. https://doi.org/10.1016/j.anireprosci.2005.06.025

Ball, B. A., Medina, V., Gravance, C. G., \& Baumber, J. (2001). Effect of antioxidants on preservation of motility, viability and acrosomal integrity of equine spermatozoa during storage at $5{ }^{\circ} \mathrm{C}$. Theriogenology, 56 , 577-589. https://doi.org/10.1016/S0093-691X(01)00590-8

Baumber, J., Ball, B. A., Gravance, C. G., Medina, V., \& Davies-Morel, M. C. (2000). The effect of reactive oxygen species on equine sperm motility, viability, acrosomal integrity, mitochondrial membrane potential, and membrane lipid peroxidation. Journal of Andrology, 21, 895-902. 
Boyne, A. F., \& Ellman, G. L. (1972). A methodology for analysis of tissue sulfhydryl components. Analytical Biochemistry, 46, 639-653. https://doi.org/10.1016/0003-2697(72)90335-1

Gibb, Z., Lambourne, S. R., \& Aitken, R. J. (2014). The Paradoxical Relationship Between Stallion Fertility and Oxidative Stress. Biology of Reproduction, 91, 1-10. https://doi.org/10.1095/biolreprod.114.118539

Johannisson, A., Lundgren, A., Humblot, P., \& Morrell, J. M. (2014). Naturally and stimulated levels of reactive oxygen species in cooled stallion semen destined for artificial insemination. Animal, 8, 1706-1714. https://doi.org/10.1017/S1751731114001499

Kankofer, M., Kolm, G., Aurich, J., \& Aurich, C. (2005). Activity of glutathione peroxidase, superoxide dismutase and catalase and lipid peroxidation intensity in stallion semen during storage at $5{ }^{\circ} \mathrm{C}$. Theriogenology, 63, 1354-1365. https://doi.org/10.1016/j.theriogenology.2004.07.005

Maia, M. D. S., Bicudo, S. D., Sicherle, C. C., Rodello, L., \& Gallego, I. C. S. (2010). Lipid peroxidation and generation of hydrogen peroxide in frozen-thawed ram semen cryopreserved in extenders with antioxidants. Animal Reproduction Science, 122, 118-123. https://doi.org/10.1016/j.anireprosci.2010.08.004

Morris, L. H., Hunter, R. H., \& Allen, W. R. (2000). Hysteroscopic insemination of small numbers of spermatozoa at the uterotubal junction of preovulatory mares. Journal of Reproduction and Fertility, 118, 95-100. https://doi.org/10.1530/jrf.0.1180095

Moubasher, A. E., El Din, A. M. E., Ali, M. E., El-Sherif, W. T., \& Gaber, H. D. (2013). Catalase improves motility, vitality and DNA integrity of cryopreserved human spermatozoa. Andrologia, 45, 135-139. https://doi.org/10.1111/j.1439-0272.2012.01310.x

Nelson, D. P., \& Kiesow, L. A. (1972). Enthalpy of decomposition of hydrogen peroxide by catalase at $25^{\circ} \mathrm{C}$ (with molar extinction coefficients of $\mathrm{H}_{2} \mathrm{O}_{2}$ solutions in the UV). Analytical Biochemistry, 49, 474-478. https://doi.org/10.1016/0003-2697(72)90451-4

Ohkawa, H., Ohishi, N., \& Yagi, K. (1979). Assay for lipid peroxides in animal tissues by thiobarbituric acid reaction. Analytical Biochemistry, 95, 351-358. https://doi.org/10.1016/0003-2697(79)90738-3

Ortega Ferrusola, C., González Fernández, L., Morrell, J. M., Salazar Sandoval, C., Macías García, B., Rodríguez-Martinez, H., ... Peña, F. J. (2009). Lipid peroxidation, assessed with BODIPY-C 11, increases after cryopreservation of stallion spermatozoa, is stallion-dependent and is related to apoptotic-like changes. Reproduction, 138, 55-63. https://doi.org/10.1530/REP-08-0484

Padilla, A. W., \& Foote, R. H. (1991). Extender and centrifugation effects on the motility patterns of slow-cooled stallion spermatozoa. Journal of Animal Science, 69, 3308-3313. https://doi.org/10.2527/1991.6983308x

Dos Santos Hamilton, T. R., De Castro, L. S., De Carvalho Delgado, J., De Assis, P. M., Siqueira, A. F. P., Mendes, C. M., ... D’Avila Assumpcao, M. E. O. (2016). Induced lipid peroxidation in ram sperm: Semen profile, DNA fragmentation and antioxidant status. Reproduction, 151, 379-390. https://doi.org/10.1530/ REP-15-0403

Sikka, S. C., Rajasekaran, M., \& Hellstrom, W. J. (1995). Role of oxidative stress and antioxidants in male infertility. Journal of Andrology, 16, 464-468.

Vidament, M., Ecot, P., Noue, P., Bourgeois, C., Magistrini, M., \& Palmer, E. (2000). Centrifugation and addition of glycerol at $22{ }^{\circ} \mathrm{C}$ instead of $4{ }^{\circ} \mathrm{C}$ improve post-thaw motility and fertility of stallion spermatozoa. Theriogenology, 54, 907-919. https://doi.org/10.1016/S0093-691X(00)00401-5

Walczak-Jedrzejowska, R., Wolski, J. K., \& Slowikowska-Hilczer, J. (2013). The role of oxidative stress and antioxidants in male fertility. Central European Journal of Urology, 66, 60-67. https://doi.org/10.5173/ceju. 2013.01.art19

Watson, P. F. (2000). The causes of reduced fertility with cryopreserved semen. Animal Reproduction Science, 481-492. https://doi.org/10.1016/S0378-4320(00)00099-3

\section{Copyrights}

Copyright for this article is retained by the author(s), with first publication rights granted to the journal.

This is an open-access article distributed under the terms and conditions of the Creative Commons Attribution license (http://creativecommons.org/licenses/by/4.0/). 